\title{
Knowledge of Breast Cancer and its Association with Preventive Practice Among Malaysian School Teachers

\section{Abstract}

Objective: The study aim was to investigate the association between knowledge of breast cancer and practice of breast self-examination (BSE) and having clinical breast examination (CBE) in a crosssectional sample of 700 Malaysian secondary school teachers.

Methodology: A two-stage sampling frame was used; a simple random sample of 10 out of 24 schools was selected and all teachers within those schools were invited to participate. The following data were collected using a self-administered questionnaire (i) sociodemographic data, (ii) five knowledge categories: general knowledge of breast cancer, signs and symptoms, risk factors, mammography, recommended frequency of BSE and CBE, and (iii) practiceof BSE and CBE.

Results: The response rate was $74 \%(518 / 700)$. Level of exercise was associated with BSE $(p=0.02)$ and $C B E(p=0.01)$, with exercise twice a week showing the strongest association compared to never exercising, $\mathrm{OR}=2.71(95 \% \mathrm{Cl}=1.38-5.33, \mathrm{p}=0.004)$ for $\mathrm{BSE}, \mathrm{OR}=2.40$ (95\% $\mathrm{Cl}=1.27-4.55, \mathrm{p}=0.007)$ for CBE. Self-report of having an annual medical check up was associated with $\mathrm{BSE}, \mathrm{OR}=2.13,(95 \% \mathrm{Cl}=1.29$ 3.52, $p<001)$ and $C B E, O R=2.41,(95 \% C l=1.57-3.70, p<001)$. Likelihood of practicing BSE improved with increasing total knowledge score (quartiles) in a dose dependent manner, Q2, OR $=1.78(95 \% \mathrm{Cl}$ 0.97-3.27), Q3OR $=1.89$ (95\% Cl 1.06-3.36), Q4OR =2.2 (95\% Cl 1.15$3.91, \mathrm{p}=0.02$ ) compared to the lowest quartile Q1 when adjusted forexercise and annual checkup. Knowledge of symptoms and signs was associated with BSE practice, OR $=1.25(95 \% \mathrm{Cl} 1.06-1.48, \mathrm{p}=0.009)$ and $C B E, O R=1.3(95 \% \mathrm{Cl} 1.08-1.57, p=0.005)$ having adjusted for exercise and annual checkup (BSE and $\mathrm{CBE}$ ) and age and marital status (CBE). General knowledge was also positively associated with BSE, $\mathrm{O}=1.39(95 \% \mathrm{Cl} 1.07-1.81, \mathrm{p}=0.01)$ after adjustment though not with CBE $(p=0.41)$. Knowledge of mammography was inversely associated
Redhwan Ahmed Al-Naggar', Muhamed T Osman²

1 Population Health and Preventive Medicine, Faculty of Medicine, Universiti Teknologi MARA (UiTM).

2 Faculty of Medicine and Defence Health, National Defence University of Malaysia, Kuala Lumpur, Malaysia.

Contact information:

Redhwan Ahmed Al-Naggar.

Address: Faculty of Medicine, Universiti Teknologi MARA (UITM).

”radhwan888@yahoo.com 
with BSE however the association was not statistically significant OR $=0.77(95 \% \mathrm{Cl} 0.56-1.05, \mathrm{p}=0.10)$.

Conclusion: Correct knowledge of symptoms and signs of breast cancer is the most important factor associated with BSE and CBE in Malaysian women after adjustment for other positive health behaviors. Knowledge of risk factors, mammography and recommended frequency of BSE and CBE were not associated with practice of BSE and CBE.

\section{Keywords}

Breast Cancer, Breast SelfExamination, Clinical Breast Examination, Malaysia.

\section{Introduction}

Breast cancer is the most common type of cancer among women worldwide and represents $14 \%$ of total cancer deaths in females in 2008. Although breast cancer prevalence in developed countries is more than developing countries, the majority of breast cancer mortality (69\%) occurs in developing countries It accounts for over one million of the estimated 10 million neoplasms diagnosed worldwide yearly.

In Malaysia, the National Cancer Registry (NCR) 2003-2005 reported an age-standardized rate (ASR) of 47.3 per 100,000 . The incidence is highest in Chinese $(59.9$ per 100,000$)$ followed by Indians (54.2 per 100,000) and Malays (34.9 per 100,000) [1]. The Penang Cancer Registry 2004-2008 reported an incidence of 48 per 100,000 [2]. The International Agency for Research in Cancer (GLOBOCAN) 2012 estimated the ASR of breast cancer in Malaysia as 38.7 per 100,000 with 5410 new cases in 2012 [3].

This high incidence of breast cancer requires high attention for health authorities. The knowledge and care-seeking attitude for breast cancer management is so low that majority of the affected patients present late in the hospital when little or nothing can be done again. This indicates a need for increased community awareness of methods for early detection of the disease [4]. Although breast cancer cannot be prevented, the risks of developing breast cancer can be minimized. Diagnosis of breast cancer during the early stage of the disease has been positively linked to a decrease in mortality, morbidity and effective cost of management of the illness. There are various methods of early detection of breast cancer. These include: Breast self-examination (BSE), clinical breast examination (CBE) and mammography screening [4].

Early detection and prompt treatment offer the greatest chance of long-term survival [5-6]. Mammography, clinical breast examination and breast self-examination (BSE) are the secondary preventive methods used for screening in the early detection of breast cancer [7]. Cancer screening tests play a pivotal role in reducing breast cancer related mortalities [8]. The American Cancer Society (ACS) recommends $C B E$ and mammography in the early detection of breast cancer [9]. According to ACS recommendations, women should know how their breasts normally feel and report any breast changes promptly to their health care providers. BSE is an option for women starting from the early $20 \mathrm{~s}[5,10]$.

Although breast self-examination (BSE) as a screening method is controversial, it has been reported that this makes women more "breast aware", which in turn may lead to earlier diagnosis of breast cancer [11] and when a woman wants to perform BSE, she should receive instructions in the technique and periodically have her technique reviewed [12]. BSE is suitable and applicable than other methods for developing countries. It is safe, non-invasive and economic [13-14]. 
This study aim was to investigate the association between knowledge of breast cancer and practice of breast self-examination (BSE) and having clinical breast examination (CBE) in a cross-sectional sample of 700 Malaysian secondary school teachers.

\section{Materials and Methods}

This cross-sectional study was conducted among 700 secondary school teachers living and teaching in Shah Alam, Selangor, Malaysia. Shah Alam is located about 25 kilometers west of the country's capital, Kuala Lumpur. A two-stage sampling frame was used; a sample of 10 out of a total of 24 secondary schools in the area was randomly selected using simple random sampling (24 equal piece of papers with the same color were prepared and written on each piece the name of school. Then put the 24 pieces in one container. Then 10 pieces were chosen randomly, and all teachers within those schools were invited to participate. Male secondary school teachers, orthose with a personal history of breast cancer were excluded from this study. Datawere collected using a self-administered questionnaire which consisted of three sections:(i) socio-demographic data, (ii) knowledge of breast cancer (five categories) and (iii) practiceof BSE and CBE. Socio-demographic data included questions on age, race, marital status, level of education, income range Ringgit Malaysia (RM), residency, specialty in teaching, family history of breast cancer, lifestyle questions, alcohol consumption, frequency of exercise and undertaking annual medical checkup. The five knowledge categories comprised: general knowledge about breast cancer, knowledge of signs and symptoms, risk factors, mammography and recommended frequency of $\mathrm{BSE}$ and $\mathrm{CBE}$, The questionnaire was distributed in English. Content and face validity of the questionnaire was established by opinion of an expert professor. A pilot study was carried out among 12 women to check face validity. Ethical approval of the study was first obtained from Unit Kajian of KementerianPelajaranMalaysia
(Research unit in Ministry of Education). After a month, permission was granted from the KementerianPelajaran Malaysia. Permission to conduct the research in the secondary schools was sought and obtained from Jabatan Pelajaran Negeri Selangor (State Department of Education). Information meetings were held with the teachers in the schools to explain the purpose of the study. Immediately before the questionnaire administered to them. Their anonymity and right to withdraw was ensured. Each participant signed a consent form. They also received a pamphlet about breast self-examination (BSE), subsequent to completion of the study questionnaires.

Analysis was performed using SPSS version 22.0. Descriptive and inferential statistics were computed for each variable. Separate knowledge scores were computed for each knowledge parameter. Each parameter was assigned equal weighting, (1 for each correct answer, 0 for each incorrect answer). Scores were summated for each of the five knowledge categories and an overall total score. To determine the effects of socio-demographic/lifestyle and knowledge on BSE and CBE practice logistic regression models using a basic ENTER and BACKWARD STEPWISE (Wald) models were developed with BSE and CBE practice as binary outcome measures. The co-varieties used in the model were the socio-demographic variables, mediantotal knowledge score, andmedianknowledge score for eachk nowledge category. To illustrate differencesin effect of high and low knowledge scores on BSE and CBE practice, total knowledge score was grouped into quartiles.

\section{Results}

The response rate from the 700 women invited to participate was $74.1 \%$ (519). Descriptive statistics are shown in Table 1. The majority (73.6\%) were aged 30-49 years and were native Malay. Almost all were married, well-educated with an average income and lived and worked in urban areas. Almost one-fifth reported a positive family history of breast 
Table 1. Socio-demographic and lifestyle characteristics of Malaysian School Teachers.

\begin{tabular}{|l|c|c|c|c|c|c|}
\hline \multicolumn{1}{|l|}{ Variable } & $\begin{array}{c}\text { Total } \\
\mathbf{n}\end{array}$ & $\%$ & $\begin{array}{c}\text { Practice } \\
\text { BSE } \mathbf{n}\end{array}$ & $\%$ & $\begin{array}{c}\text { Practice } \\
\text { CBE } \mathbf{n}\end{array}$ & $\%$ \\
\hline Age $(\mathbf{n = 5 1 9 )}$ & & & & & & \\
\hline$<29$ & 94 & 18.1 & 67 & 17.9 & 22 & 12.4 \\
\hline $30-39$ & 202 & 38.9 & 137 & 36.6 & 63 & 35.6 \\
\hline $40-49$ & 180 & 34.7 & 141 & 37.7 & 72 & 40.7 \\
\hline $50-59$ & 43 & 8.3 & 29 & 7.8 & 20 & 11.3 \\
\hline Race $(n=519)$ & & & & & & \\
\hline Malay & 471 & 90.8 & 338 & 90.4 & 156 & 88.2 \\
\hline Chinese & 22 & 4.2 & 16 & 4.3 & 9 & 5.1 \\
\hline Indian & 22 & 4.2 & 18 & 4.8 & 10 & 5.6 \\
\hline Others & 4 & 0.8 & 2 & 0.5 & 2 & 1.1 \\
\hline
\end{tabular}

Residency $(n=519)$

\begin{tabular}{|l|c|c|c|c|c|c|}
\hline Urban & 510 & 98.3 & 368 & 98.4 & 173 & 97.7 \\
\hline Rural & 9 & 1.7 & 6 & 1.6 & 4 & 2.3 \\
\hline
\end{tabular}

Marital status $(n=519)$

\begin{tabular}{|l|c|c|c|c|c|c|}
\hline Single & 45 & 8.7 & 29 & 7.8 & 9 & 5.1 \\
\hline Married & 462 & 89.0 & 338 & 90.4 & 168 & 94.9 \\
\hline Engaged & 6 & 1.2 & 2 & 0.5 & 0 & \\
\hline $\begin{array}{l}\text { Divorced/ } \\
\text { Widowed }\end{array}$ & 6 & 1.2 & 5 & 1.3 & 0 & \\
\hline
\end{tabular}

Education $(n=519)$

\begin{tabular}{|l|c|c|c|c|c|c|}
\hline $\begin{array}{l}\text { SPM/ } \\
\text { Diploma }\end{array}$ & 12 & 2.3 & 9 & 2.4 & 6 & 3.4 \\
\hline Degree & 455 & 87.7 & 326 & 87.2 & 153 & 86.4 \\
\hline Master & 52 & 10.0 & 39 & 10.4 & 18 & 10.2 \\
\hline
\end{tabular}

Specialty $(n=511)$

\begin{tabular}{|l|c|c|c|c|c|c|}
\hline Science & 160 & 31.3 & 119 & 32.5 & 52 & 30.2 \\
\hline Religion & 48 & 9.4 & 33 & 9.0 & 17 & 9.9 \\
\hline Languages & 139 & 27.2 & 97 & 26.5 & 49 & 28.5 \\
\hline $\begin{array}{l}\text { Social } \\
\text { Studies }\end{array}$ & 164 & 32.1 & 117 & 32.0 & 54 & 31.4 \\
\hline
\end{tabular}

Monthly income $(n=467)$

\begin{tabular}{|l|c|c|c|c|c|c|}
\hline $1000-2000$ & 32 & 6.9 & 21 & 6.2 & 6 & 3.8 \\
\hline $2001-3000$ & 168 & 36.0 & 123 & 36.6 & 55 & 34.4 \\
\hline $3001-4000$ & 149 & 31.9 & 111 & 32.9 & 60 & 37.4 \\
\hline $4001+$ & 118 & 25.3 & 82 & 24.3 & 39 & 24.4 \\
\hline
\end{tabular}

Family history breast cancer $(n=519)$

\begin{tabular}{l|c|c|c|c|c|c|}
\hline $\begin{array}{l}\text { Yes } \\
\text { No/Don't } \\
\text { Know }\end{array}$ & 920 & 80.9 & 310 & 82.9 & 150 & 84.7 \\
\hline $\begin{array}{l}\text { BMI }(n=431) \\
\begin{array}{l}\text { Underweight } \\
<18.5\end{array}\end{array}$ & 22 & 5.1 & 16 & 4.9 & 1 & 0.7 \\
\hline
\end{tabular}

\begin{tabular}{|c|c|c|c|c|c|c|}
\hline Variable & $\begin{array}{c}\text { Total } \\
\mathbf{n}\end{array}$ & $\%$ & $\begin{array}{c}\text { Practice } \\
\text { BSE n }\end{array}$ & $\%$ & $\begin{array}{l}\text { Practice } \\
\text { CBE n }\end{array}$ & $\%$ \\
\hline $\begin{array}{l}\text { Normal } \\
18.5-24.99\end{array}$ & 230 & 53.4 & 172 & 52.8 & 85 & 55.6 \\
\hline $\begin{array}{l}\text { Over-weight } \\
25-29.99\end{array}$ & 133 & 30.9 & 106 & 32.5 & 57 & 37.3 \\
\hline Obese 30+ & 46 & 10.7 & 32 & 9.8 & 10 & 6.5 \\
\hline \multicolumn{7}{|c|}{ Exercise/week $(n=519)$} \\
\hline Never & 126 & 24.3 & 77 & 20.6 & 25 & 14.1 \\
\hline Once & 197 & 38.0 & 143 & 38.2 & 66 & 37.3 \\
\hline Twice & 96 & 18.4 & 79 & 21.1 & 41 & 23.2 \\
\hline $\begin{array}{l}\text { Three times } \\
\text { or more }\end{array}$ & 100 & 19.3 & 75 & 20.1 & 45 & 25.4 \\
\hline \multicolumn{7}{|c|}{ Alcohol consumption $(n=519)$} \\
\hline Yes & 3 & 0.6 & 2 & 0.5 & 0 & \\
\hline No & 516 & 99.4 & 372 & 99.5 & 177 & 100.0 \\
\hline \multicolumn{7}{|c|}{ Annual Medical check-up $(n=519)$} \\
\hline Yes & 168 & 32.4 & 141 & 37.7 & 86 & 48.6 \\
\hline No & 351 & 67.6 & 233 & 62.3 & 91 & 51.4 \\
\hline
\end{tabular}

cancer. Almost all women abstained from alcohol. Over two-fifths of women (41.6\%) were overweight or obese. Almost a quarter reported never taking exercise and $37.7 \%$ reported taking exercise twice a week or more often. One-third of women reported having an annual medical check-up.

Older women (age 40-59) reported ever practicing BSE (76.1\% vs $68.9 \%$ ) and CBE $(41.3 \%$ vs $28.7 \%$ ) though the effect was only significant for $\operatorname{CBE}(p=0.003), B S E p=0.07$. Married or engaged women were more likely to practice CBE than single women (35.9\% vs $17.6 \%$ ) $p=0.009$ but not BSE (ns). Although more women without positive family history of breast cancer reported practicing BSE than those with a family history (73.8\% vs $64.6 \%)$, the effect was non-significant ( $p=0.07)$.

Taking any exercise compared to no exercise was strongly associated with BSE $(p=0.005)$ and CBE $(p<0.001)$. Obese women $(21.7 \%)$ were less likely to have CBE than overweight (42.9\%) or normal / underweight women (34.1\%), $p=0.03$. BMI and BSE were not associated (ns). Having a medical checkup in the past year was strongly associated with both BSE $(p<0.001)$ and CBE $(p<0.001)$. 
Table 2 shows the percentage of correct answers within each knowledge catergory. While 4 out of 5 women were aware that obesity is the commonest cause of death in Malaysian women and of the increased risk with age, 3 in 4 considered that it only occurred in women and 9 out of 10 women thought it was transmissible.

While the level of knowledge around symptoms was high, in excess of $80 \%$, knowledge around risk factors was mixed. Correct knowledge of risk factors

Table 2. Knowledge of Malaysian female secondary school teachers about breast cancer and risk factors $(n=431)$.

\begin{tabular}{|c|c|c|c|c|c|c|}
\hline Variable & $\begin{array}{l}\text { Total } \\
\mathrm{N}\end{array}$ & $\begin{array}{c}\% \\
\text { correct }\end{array}$ & $\begin{array}{c}\text { Practice } \\
\text { BSE } \\
\text { N }\end{array}$ & $\begin{array}{c}\% \\
\text { correct }\end{array}$ & $\begin{array}{c}\text { Practice } \\
\text { CBE } \\
\text { N }\end{array}$ & $\begin{array}{c}\% \\
\text { correct }\end{array}$ \\
\hline \multicolumn{7}{|l|}{ General Knowledge } \\
\hline Only females have breast cancer & 126 & 24.3 & 73 & 19.5 & 42 & 23.7 \\
\hline Breast cancer is transmittable & 37 & 7.1 & 18 & 4.8 & 12 & 6.8 \\
\hline $\begin{array}{l}\text { Breast cancer is the leading cause of death in Malaysian } \\
\text { women }\end{array}$ & 432 & 83.2 & 306 & 81.8 & 147 & 83.1 \\
\hline Risk of having breast cancer is $>35$ years old & 434 & 83.6 & 315 & 84.2 & 160 & 36.9 \\
\hline \multicolumn{7}{|l|}{ Knowledge of Risk Factors } \\
\hline Old age is a risk factor & 212 & 40.8 & 138 & 36.9 & 56 & 31.6 \\
\hline Family history of breast cancer is a risk factor & 493 & 95.0 & 356 & 95.2 & 172 & 97.2 \\
\hline Cigarette smoking is a risk factor & 392 & 75.5 & 286 & 76.5 & 140 & 79.1 \\
\hline Low fat diet & 91 & 17.5 & 69 & 18.4 & 31 & 17.5 \\
\hline Having first child after 30 years old & 211 & 40.7 & 154 & 41.2 & 69 & 39.0 \\
\hline Early menses & 188 & 36.2 & 151 & 40.4 & 71 & 40.1 \\
\hline Late menopause & 203 & 39.1 & 145 & 38.8 & 67 & 37.9 \\
\hline Use oral contraceptive & 133 & 25.6 & 96 & 25.7 & 47 & 26.6 \\
\hline Large breasts & 76 & 14.6 & 42 & 11.2 & 21 & 11.9 \\
\hline Breast feeding & 33 & 6.4 & 23 & 6.1 & 9 & 5.1 \\
\hline \multicolumn{7}{|l|}{ Knowledge of Symptoms } \\
\hline Painless breast lump & 440 & 84.8 & 316 & 84.5 & 147 & 83.1 \\
\hline Lump under armpit & 468 & 90.2 & 343 & 91.7 & 168 & 94.9 \\
\hline Nipple discharge & 427 & 82.3 & 319 & 85.3 & 160 & 90.4 \\
\hline Change in breast shape & 413 & 79.6 & 302 & 80.7 & 149 & 84.2 \\
\hline Pain in breast region & 412 & 79.4 & 300 & 80.2 & 146 & 82.5 \\
\hline Dimpling of breast skin & 356 & 68.6 & 269 & 71.9 & 135 & 76.3 \\
\hline \multicolumn{7}{|l|}{ Knowledge of BSE and CBE } \\
\hline $\begin{array}{l}\text { Breast Self-Examination (BSE) is recommended for } \\
\text { females once in } 6 \text { months }\end{array}$ & 375 & 72.3 & 293 & 78.3 & 141 & 79.7 \\
\hline $\begin{array}{l}\text { Clinical Breast Examination (CBE) is recommended for } \\
\text { females once a year }\end{array}$ & 412 & 79.4 & 317 & 84.8 & 157 & 88.7 \\
\hline \multicolumn{7}{|l|}{ Knowledge of mammography } \\
\hline $\begin{array}{l}\text { There is a potential risk of developing breast cancer from } \\
\text { mammography }\end{array}$ & 133 & 25.6 & 96 & 25.7 & 55 & 31.1 \\
\hline $\begin{array}{l}\text { The most appropriate age for a first mammogram is age } \\
35-45 \text { years }\end{array}$ & 357 & 68.8 & 268 & 71.7 & 131 & 74.0 \\
\hline Mammography should be carried out once a year & 314 & 60.5 & 245 & 65.5 & 119 & 67.2 \\
\hline
\end{tabular}


was $<50 \%$ except for family history and cigarette smoking. Correct knowledge around the protective effect of breastfeeding was particularly poor. Predictably, correct knowledge of the recommended frequency of BSE and CBE was associated with BSE $(p<0.001)$ and CBE practice $(p<0.001)$. Three out of four women were unaware of the link between cumulative exposure to radiation from repeat mammography and potential cancer risk.

Correct knowledge of the lifetime risk of breast cancer was associated with CBE $(p=0.003)$. Correct knowledge of symptomsand BSE and/CBE practice was significantly associated with early menses (BSE, $p=0.002$ ), large breasts (BSE $p<0.001$ ), lump under the armpit $(C B E, p=0.009)$, nipple discharge (BSE $p=0.004, C B E p<0.001)$, change in breast shape $(C B E p=0.06)$ and dimpling (BSE $p=0.009, C B E$ $\mathrm{P}=0.007)$.

Correct knowledge of the risks due to mammography was significant for CBE only $(p=0.04)$, recommended age of first mammogram for BSE $p=0.02$, and recommended frequency of mammography for BSE $(p<0.001)$ and CBE $(p<0.001)$.

Incorrect knowledge around breast cancer occurrence by gender and transmission was associated with BSE $(p<0.001)$ but not CBE (ns). Incorrect knowledge around older age being a risk factor for breast cancer was significantly associated with practice of BSE $(p<0.001)$ and CBE $(p<0.001)$.

Table 3 shows the univariate logistic model for the socio-demographic and lifestyle factors associated with self-reported practice of BSE and CBE. Criteria for entry set the significance level at 0.01. Co-varieties associated with CBE practice but not BSE were: being Malay $(p=0.08)$, living in an urban area $(p=0.05)$ and being single, widowed or divorced (0.03).

Having an income in the second highest category (3,001-4,000) was associated with BSE (0.04) and CBE (0.06).

Level of exercise was associated with BSE $(p=0.03)$ and CBE $(p=0.04)$, with exercise twice a week showing the strongest association compared to ne- ver exercising Unadj. OR=3.06 (95\% Cl=1.39-6.77, $\mathrm{p}=0.004)$ for $\mathrm{BSE}, \mathrm{OR}=2.63$ (95\% $\mathrm{Cl}=1.25-5.56$, $p=0.006)$ for CBE. Self-report of having an annual medical check up was associated with BSE, UnadjOR=1.97, (95\% Cl=1.09-3.54, $\mathrm{p}=0.02)$ and $C B E$, $\mathrm{OR}=1.99,(95 \% \mathrm{Cl}=1.21-3.28, \mathrm{p}=0.007)$.

Table 4 shows the total and individual knowledge scores associated with BSE and CBE adjusted for the significant socio-demographic and lifestyle covariates and age (multivariable analysis). Likelihood of practicing BSE improved with increasing total knowledge score (quartiles) in a dose dependent manner $\{\mathrm{Q} 2, \mathrm{OR}=1.78(95 \% \mathrm{Cl} 0.97-3.27), \mathrm{p}=0.06\}$, $\{\mathrm{Q} 3, \mathrm{OR}=1.89(95 \% \mathrm{Cl} 1.06-3.36, \mathrm{p}=0.03), \mathrm{Q} 4, \mathrm{OR}$ $=2.12(95 \% \mathrm{Cl} 1.15-3.91, \mathrm{p}=0.02)$ compared to the lowest quartile Q1 when adjusted forage, income range, exercise and annual check up. Total knowledge score and CBE were not associated (ns). A higher knowledge of symptoms score was associated with BSE practice, $O R=1.25(95 \% \mathrm{Cl} 1.06-1.47, \mathrm{p}=0.009)$ and $C B E, O R=1.31(95 \% \mathrm{Cl} 1.09-1.59, p=0.004)$ having adjusted for exercise and annual check up (BSE and CBE) and age and marital status (CBE). A higher general knowledge score was also positively associated with BSE, OR=1.39 (95\% Cl 1.07-1.81, $\mathrm{p}=0.01$ ) after adjustment though not with $\mathrm{CBE}$ $(p=0.41)$. Greater knowledge of mammography was inversely associated with BSE however the association was not statistically significant OR $=0.76(95 \%$ $\mathrm{Cl}$ 0.56-1.05, $\mathrm{p}=0.09$ ).

The best predictors of BSE were increasing overall Knowledge Score in a dose dependent manner, exercise particularly twice a week or more and having an annual check up. When separate scores are considered higher symptom scores/general knowledge scores with exercise and annual check up were the best predictors.

Only a high symptom score with exercise particularly twice or more per week increased the likelihood of CBE practice 


\section{INTERNATIONAL ARCHIVES OF MEDICINE

Table 3. Socio-demographic and lifestyle factors associated with BSE and CBE.

\begin{tabular}{|c|c|c|c|c|c|c|c|}
\hline \multirow[b]{2}{*}{ Variable } & \multirow[b]{2}{*}{$\mathbf{N}$} & \multicolumn{3}{|c|}{ BSE } & \multicolumn{3}{|c|}{ CBE } \\
\hline & & \$OR & $95 \% \mathrm{Cl}$ & $p$-value & \$OR & $95 \% \mathrm{Cl}$ & p-value \\
\hline Age & 519 & 0.98 & $0.93-1.03$ & 0.47 & 1.02 & $0.98-1.07$ & 0.38 \\
\hline \multicolumn{8}{|l|}{ Race } \\
\hline Malay & 347 & 2.50 & $0.85-7.36$ & 0.97 & 2.26 & $0.92-5.56$ & 0.08 \\
\hline Non-Malay & 31 & 1 & & & 1.00 & & \\
\hline \multicolumn{8}{|l|}{ Residency } \\
\hline Urban & 371 & 2.52 & $0.26-24.8$ & 0.43 & 11.92 & $0.97-146.8$ & 0.05 \\
\hline Rural & 7 & 1 & & & 1 & & \\
\hline \multicolumn{8}{|l|}{ Marital status } \\
\hline Single/Divorced/Widowed & 30 & 1.04 & $0.38-2.79$ & 0.95 & 5.05 & $1.22-20.94$ & $\star 0.03$ \\
\hline Married/Engaged & 348 & 1 & & & 1 & & \\
\hline \multicolumn{8}{|l|}{ Education } \\
\hline SPM/Diploma & 12 & 1 & & & 1 & & \\
\hline Degree & 455 & 1.57 & $0.31-8.01$ & 0.59 & 0.52 & $0.10-2.77$ & 0.44 \\
\hline Master & 52 & 1.41 & $0.24-8.48$ & 0.71 & 0.41 & $0.07-2.50$ & 0.34 \\
\hline \multicolumn{8}{|l|}{ Specialty } \\
\hline Science & 132 & 1 & & & 1 & & 0.58 \\
\hline Religion & 37 & 1.18 & $0.48-2.88$ & 0.72 & 1.62 & $0.70-3.78$ & 0.26 \\
\hline Languages & 95 & 0.89 & $0.44-1.81$ & 0.74 & 0.86 & $0.44-1.67$ & 0.66 \\
\hline Social Studies & 114 & 1.03 & $0.48-1.67$ & 0.73 & 1.03 & $0.57-1.86$ & 0.92 \\
\hline \multicolumn{8}{|l|}{ Monthly income } \\
\hline $1000-2000$ & 28 & 1 & & & 1 & & \\
\hline 2001-3000 & 147 & 1.77 & $0.66-4.77$ & 0.26 & 3.86 & $0.76-19.73$ & 0.11 \\
\hline $3001-4000$ & 119 & 3.21 & $1.04-9.93$ & *0.04 & 5.08 & $0.94-27.54$ & 0.06 \\
\hline $4001+$ & 84 & 2.53 & $0.66-9.71$ & 0.18 & 4.45 & $0.72-27.44$ & 0.11 \\
\hline \multicolumn{8}{|l|}{ Positive family history } \\
\hline Yes & 68 & 1.03 & & & 0.89 & $0.47-1.68$ & 0.71 \\
\hline No/ Don't Know & 310 & 1 & $0.54-1.98$ & 0.92 & 1 & & \\
\hline \multicolumn{8}{|l|}{$\mathrm{BMI}$} \\
\hline Under/ Normal weight & 219 & 1 & & & 1 & & \\
\hline Overweight /Obese & 159 & 1.26 & $0.73-2.16$ & 0.40 & 1.19 & $0.72-1.95$ & 0.50 \\
\hline \multicolumn{8}{|l|}{ Exercise/week } \\
\hline Never & 85 & 1 & & & 1 & & \\
\hline Once & 146 & 2.01 & $1.09-3.71$ & $\star 0.03$ & 1.96 & $1.01-3.81$ & $\star 0.047$ \\
\hline Twice & 79 & 3.06 & $1.39-6.77$ & $\star 0.006$ & 2.63 & $1.25-5.56$ & $\star 0.01$ \\
\hline Three times or more & 68 & 1.67 & $0.79-3.49$ & 0.18 & 2.71 & $1.26-5.87$ & $\star 0.01$ \\
\hline \multicolumn{8}{|l|}{ Alcohol consumption } \\
\hline Yes & 3 & 3.06 & $0.23-40.50$ & 0.40 & $1.13 E+9$ & & 0.99 \\
\hline No & 516 & 1 & & & 1 & & \\
\hline \multicolumn{8}{|l|}{ Annual Medical check-up } \\
\hline Yes & 123 & 1.97 & $1.09-3.54$ & $* 0.02$ & 1.99 & $1.21-3.28$ & $\star 0.007$ \\
\hline No & 255 & 1 & & & 1 & & \\
\hline
\end{tabular}


Table 4. Total and individual knowledge scores associated with BSE and CBE.

\begin{tabular}{|c|c|c|c|c|c|c|c|}
\hline \multirow[b]{2}{*}{ Variable } & \multirow[b]{2}{*}{$\mathbf{N}$} & \multicolumn{3}{|c|}{ BSE } & \multicolumn{3}{|c|}{ CBE } \\
\hline & & \$OR & $95 \% \mathrm{Cl}$ & p-value & \$OR & $95 \% \mathrm{Cl}$ & $p$-value \\
\hline Total Knowledge Score & & 1.09 & $1.00-1.18$ & 0.06 & 1.07 & $0.98-1.16$ & 0.12 \\
\hline \multicolumn{8}{|l|}{ Total Knowledge Score (Quartiles) } \\
\hline Quartile (1)8-13 & 98 & 1 & & & 1 & & \\
\hline Quartile (2) 14-15 & 137 & 1.78 & $0.97-3.27$ & 0.06 & 1.24 & $0.66-2.34$ & 0.52 \\
\hline Quartile (3) 16-17 & 153 & 1.86 & $1.06-3.36$ & *0.03 & 1.47 & $0.80-2.71$ & 0.22 \\
\hline Quartile (4) 18+ & 131 & 2.12 & $1.15-3.91$ & $\star 0.01$ & 1.63 & $0.89-3.03$ & 0.12 \\
\hline \multicolumn{8}{|l|}{ Individual Knowledge Scores } \\
\hline General Knowledge Score & 467 & 1.39 & $1.07-1.81$ & *0.01 & 1.13 & $0.86-1.48$ & 0.41 \\
\hline Risk Factor Score & 467 & 1.06 & $0.92-1.21$ & 0.42 & 0.98 & $0.85-1.11$ & 0.70 \\
\hline Symptom Score & 467 & 1.25 & $1.06-1.47$ & $\star 0.009$ & 1.31 & $1.09-1.59$ & $\star 0.004$ \\
\hline BSE, CBE Knowledge Score & 467 & 0.73 & $0.44-1.23$ & 0.24 & 1.03 & $0.62-1.69$ & 0.919 \\
\hline Mammograpy Knowledge Score & 467 & 0.76 & $0.56-1.05$ & 0.09 & 1.09 & $0.8-1.49$ & 0.58 \\
\hline
\end{tabular}

$\$$ Adjusted for age, income range, exercise, annual check-up. \$Adjusted for age, marital status, race, residency, income range, exercise, annual check-up. * $p<0.05$

\section{Discussion}

Breast cancer if detected early, is curable in $90 \%$ of the cases, but the tragedy is that most patients do not come to a doctor till there is very little that can be done. Breast self-examination has been recommended as an important method for early detection of breast cancer as in $85 \%$ cases there is five year survival rate when it is detected and treated early at the localized stage and the survival rate decreased to $56 \%$ once breast cancer is detected later with the involvement of regional lymph nodes [15].

Breast self-examination (BSE) is a simple, costfree, and easily applicable method. BSE, although not having been shown to be effective in reducing mortality, is remarkably effective in increasing selfresponsibility about health, encouraging adoption of preventive health behaviors, and creating awareness about breast cancer among women [16-17]. However, several studies conducted in Malaysia demonstrated lack of BSE practices [17].

This study reported that marital status significantly influenced the CBE practice. These may be due to the fact that married women were more exposed to health care facilities and health care professionals during follow up at pregnancy and delivery. Several studies have indicated that marital status is a consistent correlate of breast cancer screening behavior [18-19]. A similar finding was indicated that performing BSE was significantly related to marital status and breast cancer screening programme [20].

Physical activity in breast cancer prevention may not have been disseminated widely enough, even if individuals had high knowledge about breast cancer risk. Exercise was associated with BSE and CBE. Similar studies reported that exercise is significantly influenced the practice of BSE [21-22]. Previous studies showed a low level of awareness about the role of physical activity in cancer prevention regardless of country or type of cancer [23-24]. In Japan, the Cancer Control Act which indicates the need to inform individuals about the effect of lifestyle including physical activity on health and cancer prevention [25] was implemented in 2007. Awareness is considered an essential first step in changing physical activity behavior [26]. Therefore, it may be especially important to make an effort to 
increase women's awareness of the role of physical activity in breast cancer prevention. In addition, it would be necessary to design segmented information campaigns for people who respond differently to information. Regular physical activity and exercise habits are effective not only for breast cancer prevention but also for the prevention of other diseases. Thus there may be women, for example, without awareness of the effective role of physical activity in breast cancer prevention, but who take regular physical activity or exercise.

In current study, self-report of having an annual medical checkup was associated with BSE, (95\% $\mathrm{Cl}=1.29-3.52, \mathrm{p}<001)$ and $\mathrm{CBE}(95 \% \mathrm{Cl}=1.57-3.70$, $\mathrm{p}<001)$.Similarly, a study showed that women who previously had early screening had better knowledge scores, which indicates an effective interaction between awareness and screening [27]. This result also implies that well-conducted health education programs lead to better health practices [28].

Practicing BSE improves with increasing total knowledge score. Similarly Kaur and Walia, 2007 [29], observed that the students with higher qualification had better knowledge regarding BSE and their practices corresponded to their levels of knowledge. Thus an inference can be drawn that a need for continuing medical education for nursing professionals cannot be overemphasized. Levels of awareness have a definite binding on appropriate behavioural changes. Teachers as the main source of information regarding BSE has also been reported by the majority of the students $(76.6 \%)$ in the present study followed by other sources such as friends, mother and media [29].

General knowledge was also positively associated with $\mathrm{BSE}, \mathrm{OR}=1.39$ (95\% Cl 1.07-1.81, $\mathrm{p}=0.01)$ and correct knowledge of symptoms and signs of breast cancer is the most important factor associated with BSE and CBE in Malaysian women after adjustment for other positive health behaviours. Breast cancer is preventable if detected early enough [30]. Symptom detection was the initial step in the help seeking process. In this study, Knowledge of symptoms and signs was associated with BSE practice, and CBE. Lack of knowledge, not having any symptoms and being scared of getting diagnosed with breast cancer were the main barriers to practicing BSE [21- 22].

Although there is no clear evidence to support the efficacy of BSE in decreasing breast cancer mortality [31], "breast awareness is still important" [32]. Studies reported that self-awareness is more effective than BSE [32] and it appears that BSE training could provide an opportunity to increase women's knowledge about breast cancer in developing countries [33-34].

In this study $84.8 \%$ reported that Painless breast lumpis one of the symptoms of breast cancer. Lower percentage was reported byUche, 1999 [35] that only $32 \%$ of the women having knowledge of breast lump as a warning sign for breast cancer. More recent study found that only $21.4 \%$ women were aware of a painless breast lump as a common presentation of breast cancer [36]. However, another study reported that over $70 \%$ of the surveyed women were able to identify painless breast lump as symptoms of breast cancer [37].

\section{Conclusions}

Correct knowledge of symptoms and signs of breast cancer is the most important factor associated with BSE and CBE in Malaysian women after adjustment for other positive health behaviours. Knowledge of risk factors, mammography and recommended frequency of BSE and CBE were not associated with practice of BSE and CBE.

\section{Conflict of Interests}

The authors declare that there is no conflict of interestsregarding the publication of this paper. 


\section{References}

1. Lim GCC RS, Halimah Y. (Eds.) Cancer Incidence in Peninsular Malaysia 2003-2005. National Cancer Registry. Kuala Lumpur, 2008.

2. Azizah et al. Penang Cancer Registry, 2004-2008.

3. Globocan project. Estimated incidence, mortality and prevalence worldwide in 2012. Available at http://globocan.iarc.fr/Pages/ fact sheets cancer.aspx, visited on 23rd July 2015.

4. Obaii et al. "Awareness and Practice of Breast Self-Examination among Market Women in Abakaliki, South East Nigeria" Ann Med Health Sci Res., vol. 3, no. 1, pp. 7-12, 2013.

5. Dündar et al. "The knowledge and attitudes of breast selfexamination and mammography in a group of women in a rural area in western Turkey" BMC Cancer, vol. 6, no. 43, 2006.

6. Sadler GR, Dhanjal SK, Shah RB, Ko C, Anghel M, Harshburger, "Asian India women: knowledge, attitudes and behaviors toward breast cancer early detection" Public Health Nursing, vol. 18, pp. 357-363, 2001.

7. Fung SY, "Factors associated with breast self-examination behaviour among Chinese women in Hong Kong" Patient Educationand Counselling, vol. 33, pp. 233-243, 1998.

8. Tang TS, Solomon LJ, McCracken LM "Cultural barriers to mammography, clinical breast exam, and breast self-exam among Chinese-American women 60 and older" Preventive Medicine, vol. 31, pp. 575-583, 2000.

9. Smith RA, Saslow D, Sawyer KA, Costanza ME, Evans WP, Foster RS, Hendrick E, Eyre HJ, Sener S, "American cancer society guidelines for breast cancer screening uptade". Cancer J Clin, pp. 141-169, 2003.

10. Lee EH,"Breast self-examination performance among Korean nurses". Journal for Nurses in Staff Development, vol. 2, pp. 8187, 2003.

11. Akhigbe AO, Omuemu VO, "Knowledge, attitudes and practice of breast cancer screening among female health workers in a Nigerian urban city, vol. 9, pp. 203, 2009

12. Smith RA, Cokkinides V, Brooks D, et al., "Cancer screening in the United States, 2010: a review of current American Cancer Society guidelines and issues in cancer screening", CA Cancer J Clin, vol. 60, pp. 99-119, 2010.

13. Karayurt O, Dramali A, "Adaptation of Champion's Health Belief Model Scale for Turkish women and evaluation of the selected variables associated with breast self-examination"Cancer Nurs, vol. 30, pp. 69-77, 2007
14. Akpınar et al. "Knowledge and Practice of Breast Cancer Screening among Female Health Care Professionals in Turkey"Asian Pacific J Cancer Prev, vol. 12, pp. 3063-3068, 2012.

15. American cancer society, "Breast Cancer Facts \& Figures 20092010", Atlanta: American cancer society, Inc.

16. Habib F, Salman S, Safwat M, Shalaby S, "Awareness and knowledge of breast cancer among university students in al madina al munawara region" Middle East Journal of Cancer, 1, 159-66, 2010

17. Suh MA, Atashili J, Fuh EA, Eta VA, "Breast self-examination and breast cancer awareness in women in developing countries: a survey of women in Buea, Cameroon", BMC Res Notes, vol. 9, pp.627, 2012.

18. Al-Dubai SA, Qureshi AM, Saif-Ali R, Ganasegeran K, Alwan MR, Hadi JI,"Awareness and knowledge of breast cancer and mammography among a group of Malaysian women in Shah Alam", Asian Pac J Cancer Prev, vol. 12, no. 10, pp. 2531-2538, 2011.

19. Martín-López R, Jiménez-García $R$, Lopez-de-Andres $A$, Hernández-Barrera V, Jiménez-Trujillo I, Gil-de-Miguel A, Carrasco-Garrido $\mathrm{P}$, "Inequalities in uptake of breast cancer screening in Spain: analysis of a cross-sectional national survey" Public Health, vol. 127, no. 9, pp. 822-827, 2013.

20. Montazeri, A., Vahdaninia, M., Harirchi, I., Harirchi, A.M., Sajadian, A., Khaleghi, F., Ebrahimi, M., Haghighat, S., \&Jarvandi, $S$, "Breast cancer in Iran: need for greater women awareness of warning signs and effective screening methods", Asia Pacific family Medicine, vol. 7, pp. 6, 2008.

21. Al-Naggar RA \& Osman MT, "Quality of Life among Breast Cancer Patients Survival", LAP LAMBERT Academic Publishing, Germany. ISBN 978-3-659-33012-4, 2013

22. Al-Naggar RA \& Osman MT, "Young women perceptions towards genetic testing of breast cancer", Biology and Medicine, vol. 5, pp. 91-97, 2013

23. Coups EJ, Hay J, Ford JS,"Awareness of the role of physical activity in colon cancer prevention", Patient Educ Couns, vol. 72, no. 2, pp. 246-251, 2008.

24. Keighley MR, O'Morain C, Giacosa A, Ashorn M, Burroughs A, Crespi $\mathrm{M}$, et al., " Public awareness of risk factors and screening for colorectal cancer in Europe", Eur J Cancer Prev, vol. 13, no. 4, pp. 257-262, 2014

25. Ministry of Health, Labour and Welfare, Japan, "Cancer Control Act 2007". http://www.mhlw.go.jp/shingi/2007/04/dl/s04053a.pdf (In Japanese).

26. Cavill N, Bauman A, "Changing the way people think about health-enhancing physical activity: do mass media campaigns have a role?"J Sports Sci, vol. 22, no. 8, pp. 771-790, 2004.

27. Liu et al., "Breast cancer awareness among women in Eastern China: a cross-sectional study", BMC Public Health, vol. 14, pp. 1004, 2014. 
28. Doshi D, Reddy BS, Kulkarni S, Karunakar P, "Breast selfexamination: knowledge, attitude, and practice among female dental students in Hyderabad City, India", Indian J Palliat Care, vol. 18(1): 68-73, 2012.

29. Kaur S. and Walia I., "Knowledge and practices of breast self examination among nursing students", Nursing and Midwifery Research Journal, vol. 3, no. 3, pp. 128-137, 2007.

30. World Health Organization, "Breast cancer: prevention and control", Geneva, Switzerland: WHO; 2013. http://www.who. int/cancer/detection/breastcancer/en/.

31. McCready T, Littlewood D, Jenkinson J, "Breast self-examination and breast awareness: a literature review", Journal of Clinical Nursing, vol. 14, pp. 570-578, 2005

32. Austoker J, "Breast self examination: Does not prevent deaths due to breast cancer, but breast awareness is still important", BMJ, vol. 326, pp. 1-2, 2003.

33. Dye TD, Bogale $S$, Hobden C, Tilahun $Y$, Deressa $T$, et al., "Experience of initial symptoms of breast cancer and triggers for action in Ethiopia", Int J Breast Cancer. doi:10.1155/2012/908547, 2012.

34. Ceber E, Turk M, Ciceklioglu M, "The effects of an educational program on knowledge of breast cancer, early detection practices and health beliefs of nurses and midwives", Journal of Clinical Nursing, vol. 19, pp. 2363-2371, 2010.

35. Uche EE, "Cancer awareness among a Nigerian population", Trop Doct, vol. 29, no. 1, pp. 39-40, 1999.

36. Sharma et al.,"Knowledge, attitude and preventive practices of South Indian women towards breast cancer", The Health Agenda, vol. 1, no. 1, pp. 16-22, 2013.

37. Grunfeld EA, Ramirez AJ, Hunter MS, Richards MA, "Women's knowledge and beliefs regarding breast cancer", Br J Cancer, vol. 86, no. 9, pp. 1373-1378, 2002.

\section{Comment on this article:}
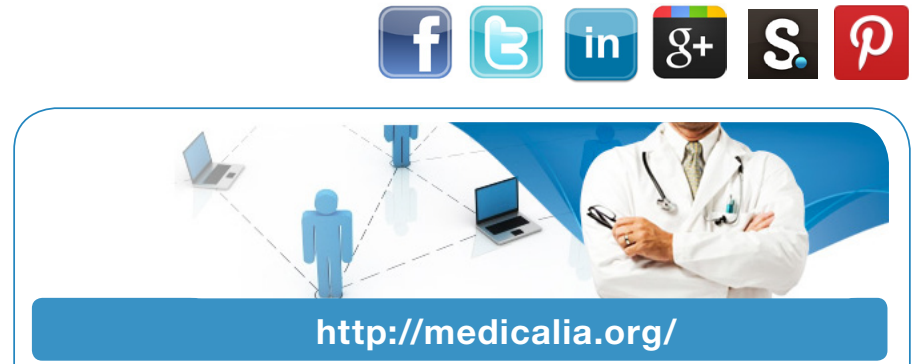

Where Doctors exchange clinical experiences, review their cases and share clinical knowledge. You can also access lots of medical publications for free. Join Now!

\section{Publish with iMedPub}

http://www.imed.pub

International Archives of Medicine is an open access journal publishing articles encompassing all aspects of medical science and clinical practice. IAM is considered a megajournal with independent sections on all areas of medicine. IAM is a really international journal with authors and board members from all around the world. The journal is widely indexed and classified Q1 in category Medicine. 